\title{
Multiphase buck converter with minimum time control strategy for RF envelope modulation
}

\author{
P. M. Cheng, M. Vasić, O. Garcia, J. A. Oliver, P. Alou. J. A. Cobos \\ Centro de Electrónica Industrial, Universidad Politécnica de Madrid \\ Madrid, Spain \\ pengming.cheng@upm.es
}

\begin{abstract}
Power amplifier supplied with constant supply voltage has very low efficiency in the transmitter. A DC-DC converter in series with a linear regulator can be used to obtain voltage modulation. Since this converter should be able to change the output voltage very fast, a multiphase buck converter with a minimum time control strategy is proposed. To modulate supply voltage of the envelope amplifier, the multiphase converter works with some particular duty cycle $(i / n, i=1,2 \ldots n, n$ is the number of phase) to generate discrete output voltages, and in these duty cycles the output current ripple can be completely cancelled. The transition times for the minimum time are pre-calculated and inserted in a look-up table. The theoretical background, the system model that is necessary in order to calculate the transition times and the experimental results obtained with a 4-phase buck prototype are given.
\end{abstract}

\section{INTRODUCTION}

The solutions for the high frequency power amplifiers can be classified two different families of power amplifiers: linear and nonlinear. The linear power amplifiers (classes A, $B$ or $A B$ ) are known to be highly linear, but inefficient solutions. On the other hand, the nonlinear power amplifiers have high power efficiency and their output is a sinusoidal signal with constant envelope. They are based on the idea to use transistors as switches instead as a current source. In that way the power losses of the devices are lower and these amplifiers are presented with classes C, D, E and F.

In order to increase the spectral efficiency the modern telecommunication systems use complex modulations that are based on multicarrier signals and result in complex envelopes that require high linearity. These envelopes have high peak to average power ratio and the linear power amplifiers, due to this signal property, have extremely low efficiency. Because of the low efficiency of the linear solutions there has been a lot of research with the idea to extend the area of application of highly efficient non linear classes. This topic became important especially with the fast development of the digital wide bandwidth applications where the non constant envelope signals are applied and the necessary linearity of the power amplifier is very high.

Until now, several techniques have been used in order to increase the linearity: Back-Off, predistortion, Doherty, Outphasing, Khan's technique (Envelope Elimination and

This work has been supported by the Ministry of Education and Science of Spain for the project TEC2009-14307-C02-01
Restoration, EER), etc. Almost all of these techniques have not been able to provide high linearity and high efficiency in the complete range of the transmitted signal. Only the Kahn's technique has showed that it is capable to linearize highly non linear power amplifier (for example class E) and to provide relatively high efficiency. This technique is based on the use of one highly efficient, but non linear power amplifier that is used for the phase modulation, together with an envelope amplifier that has to have high efficiency and provide envelope modulation by modulating the voltage supply of the non linear power amplifier. Simplified block schematic of one Kahn's transmitter can be seen in Fig.1. Basically, this technique exploits the fact that any narrow band signal can be correctly defined by knowing its envelope and phase.

Although the Kahn's technique is very well known since the 50's of the last century there have been various issues that have stopped this technique to be massively exploited. Some of these problems are the limited bandwidth of the dcdc converters that are normally employed as the solution for the envelope amplifier and the impossibility for the semiconductor devices to operate at high frequencies and wide bandwidths due to the technology limits that are reflected as the maximal voltages, parasitic capacities, rise and fall times of the devices and parasitic effects of the package where the transistors are placed

Similar approach for the reduction of the energy consumption is envelope tracking (ET). In this technique the envelope amplifier is used to supply a linear power amplifier with minimal needed voltage. Figure 2 shows a block

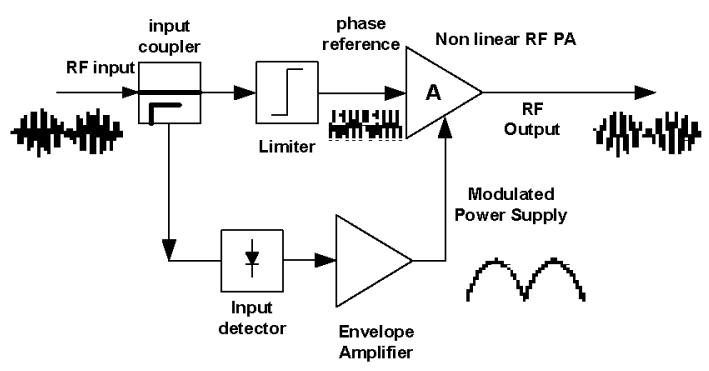

Figure 1. Block schematic of a tranismitter based on Kahn's technique 
schematic of this approach.

In the state of the art, several solutions for the envelope amplifier can be found, such as a simple buck converter in [1], multiphase buck converter in [2], and three-level converter in [3]. In all these solutions the employed switching dc-dc converters operate using PWM and this limits the possible bandwidth of the envelope amplifier, because for the high bandwidth envelope it is needed to apply high switching frequency that leads to heavy switching losses. In [4], the idea is to employ a buck converter that uses low switching frequency in parallel with a linear regulator. In this case it is possible to obtain high efficiency because the major part of the output power is managed by the buck converter, while the fast dynamic response is guaranteed by the linear regulator. A solution that exhibits a fast dynamic response and high output power is presented in $[5,6]$. The main idea is to exploit good dynamic characteristics of the multilevel converter and to increase its efficiency. Fig. 3 shows relevant time diagrams. In this solution a multilevel converter is put in series with a linear regulator, and the multilevel converter can be implemented by using different concepts, independent voltage cells [5], independent voltage sources [6] or multiphase topology that employs special PWM modulation [7]. A similar solution that employs a multilevel converter in parallel with a linear regulator has been presented in [8]. The multilevel converter is implemented as an 8-phase buck converter that operates with duty cycles that provide current ripple cancelation in order to decrease the value of the output capacitor.

In this paper an approach to implement a multilevel converter that can be combined with a linear regulator in

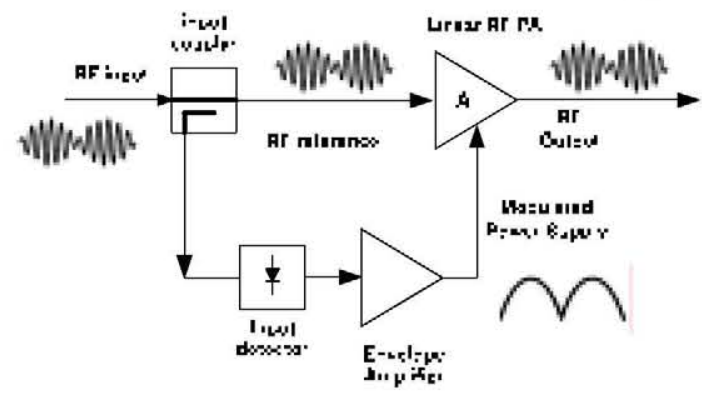

Figure 2. Block schematic based on envelope tracking

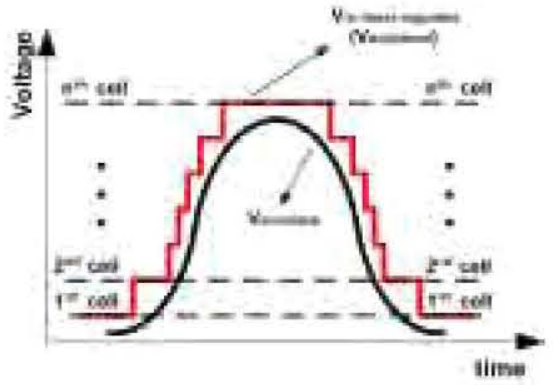

Figure 3. Time waveforms of the envelope amplifier based on a multilevel converter in series with a linear regulator order to modulate the power supply of envelope amplifier in EER or ET is presented. Like the method in [8], the multilevel converter is implemented using an $\mathrm{N}$-phase buck converter, like it is shown in Figure 4, but the voltage transients are obtained by employing the minimum time control that has been used in several applications $[9,10]$. In [9], it is used to implement a fast power supply that can be used for Dynamic Voltage Scaling (DVS) applications. The capacitor-charge balance algorithm is explained in [10], which is suitable for load step and has good current balance during the transient and after that. In this paper a simple and simple hardware implementation control strategy with lookup table to control the transient is proposed. Only several discrete voltage levels will be permitted. The converter will only work at fixed duty cycles $(\mathrm{i} / \mathrm{n}, \mathrm{i}=1,2 \ldots \mathrm{n}, \mathrm{n}$ is the number of phase) to take advantage of current ripple cancellation and provide easier calculation of the minimum time transient. It is compatible with the envelope amplifier in [5].

\section{MINIMUN TIME CONTROL IN A MULTIPHASE BUCK CONVERTER}

\section{A. Review of the minimun time control law}

The minimum time control is a control based on the Maximum Principle or Pontriagyn's Principle [9]. In the case of a buck converter this theorem provides means to change the buck's output voltage in the minimum time by controlling the on and off states of the buck's switches. Even more, it can be shown that this voltage transient can be obtained by closing and opening the main switch just once.

The idea in this paper is to use a multiphase converter with fixed duty cycles. When it is necessary to change the output voltage level, The pre-calculated on and off times for the main switch are applied in order to change it in the minimum time without voltage over/under shoot. Each phase has its own on and off times to assure that the circuit will be close to the new steady-state condition after the transient. The transient starts when one of the phases finishes its PWM cycle. In order to do it is necessary to calculate the charge flow through the inductors precisely. An approximation is made by assuming that the output voltage is changed linearly. Another important issue is that it is necessary to include the information regarding the current ripple of the each phase in the calculus in order to avoid the errors. The complete methodology for the calculation of the transient time is presented in the following section.

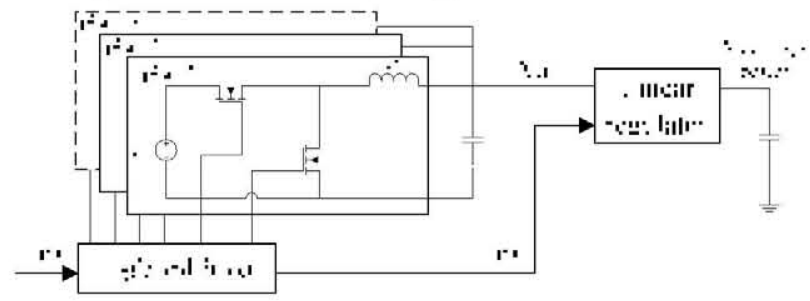

Figure 4. Multiphase buck converter in series with a linear regulator 


\section{B. Control strategy in multiphase buck converter}

In order to calculate the minimum time and the intervals during which the main switch in the buck converter is turned on and off in multiphase buck converter, it is necessary to analyze the charge flow in each one phase of the multiphase buck converter.

The assumption that the output voltage changes linearly during the transient is made:

$$
V_{\text {out }}(t)=V_{1}+\frac{\Delta \mathrm{V}}{\Delta t} t
$$

Where $V_{1}$ is the buck's output voltage before the transient starts, $\Delta \mathrm{t}$ is the duration of the transient and $\Delta \mathrm{V}$ is the voltage difference of the output's voltage after and before the transient. During the transient time, from initial voltage $\left(V_{1}\right)$ to the final voltage $\left(V_{2}\right)$, the output capacitor will receive the charge of

$$
Q_{\mathrm{C}}=\mathrm{C}\left(\mathrm{V}_{2}-\mathrm{V}_{1}\right)=\mathrm{C} \cdot \Delta \mathrm{V}
$$

where $\mathrm{C}$ is the value of the output capacitor. During the same time the load will receive the charge of:

$$
Q_{\text {LOAD }}=\mathrm{I}_{\text {LOAD }} \cdot \Delta \mathrm{t}
$$

Here it is assumed that the load is a current source (if the load is a linear regulator and the voltage change is sufficiently fast so that the load's current is constant, i.e. the envelope is not changed significantly). All that charge will come from the converter's inductors and it can be calculated as:

$$
\sum_{\mathrm{i}=1}^{\mathrm{N}} Q_{\mathrm{Li}}=\mathrm{Q}_{\mathrm{C}}+\mathrm{Q}_{\mathrm{LOAD}}
$$

where $\mathrm{Q}_{\mathrm{Li}}$ is the charge provided by each phase of the multiphase converter. If it is assumed that the voltage change is linear, which is close to the actual response, the charge of one phase, $\mathrm{Q}_{\mathrm{Li}}$, can be calculated as:

$$
Q_{L i}=I_{i} \Delta t-\frac{V_{i n}}{2 L} t_{O N, i}^{2}-\frac{V_{1}}{2 L} \Delta t^{2}+\frac{V_{i n} t_{O N, i} \Delta t}{L}-\frac{\Delta V \Delta t^{2}}{6 L}
$$

where $I_{i}$ is the $i^{\text {th }}$ inductor's current before the transient, $\mathrm{t}_{\mathrm{ON}, \mathrm{i}}$ is the time interval during which the main switch of the $\mathrm{i}^{\mathrm{th}}$ phase is turned on and $\mathrm{L}$ is the value of the inductor in each phase. It can be seen that the charge through each phase depends on the current through each phase before the transient. When the equation (5) is substituted in equation (4) it is clear that the total charge depends on the sum of the phase currents. If the duty cycle of the multiphase converter is chosen as $\mathrm{i} / \mathrm{n}$ ( $\mathrm{i}=1 \ldots \mathrm{n}, \mathrm{n}$ is the number of the converters) the sum of phase currents is always equal to the load's current, otherwise there will always be a small portion of the current that goes to the capacitor due to the voltage ripple. Therefore, by selecting the duty cycles of $\mathrm{i} / \mathrm{n}$ not only the output voltage has lower ripple, but the calculation of the transient time is more exact.

For each phase it can be written:

$$
L \Delta I_{i}=V_{\text {in }} t_{\text {on }, i}-V_{1} \Delta t-\frac{1}{2} \Delta V \Delta t
$$

where $\Delta \mathrm{I}_{\mathrm{i}}$ is the difference of the phase current after and before the transient (Fig.5). Equation (6) leads to

$$
\begin{aligned}
& t_{o n, i}=K \Delta t+\frac{L \Delta I_{i}}{V_{i n}}, \quad K=\frac{V_{1}+\frac{\Delta V}{2}}{V_{i n}} \\
& t_{o n, i}^{2}=K^{2} \Delta t^{2}+\frac{L^{2} \Delta I_{i}^{2}}{V_{i n}^{2}}+\frac{2 K L}{V_{i n}} \Delta t \Delta I_{i}
\end{aligned}
$$

It can be shown that for the selected duty cycles the following equation always holds that

$$
\sum_{\mathrm{i}=1}^{\mathrm{N}} \Delta I_{\mathrm{i}}=0
$$

Combining equations (7-9) it can be obtained

$$
\begin{gathered}
\sum_{\mathrm{i}=1}^{\mathrm{N}} t_{\text {on, } \mathrm{i}}=n K \Delta t \\
\sum_{\mathrm{i}=1}^{\mathrm{N}} t_{o n, i}^{2}=n K^{2} \Delta t^{2}+\frac{L^{2}}{V_{\text {in }}^{2}} \sum_{\mathrm{i}=1}^{\mathrm{N}} \Delta I_{i}^{2}
\end{gathered}
$$

Since the parameters of the converter and the transient voltages $\left(\mathrm{V}_{1}, \mathrm{~V}_{2}\right)$ are known, $\sum_{\mathrm{i}=1}^{\mathrm{N}} \Delta I_{i}^{2}$ can be calculated. By using (4), (5), (10) and (11), the following equation is obtained

$$
\begin{aligned}
C \Delta V+I_{\text {load }} \Delta t & =\Delta t^{2}\left(-\frac{V_{i n}}{2 L} n K^{2}+\frac{V_{i n}}{L} n K-\frac{V_{1}}{2 L} n-\frac{\Delta V}{6 L} n\right) \\
& +\Delta t I_{\text {load }}-\frac{L}{2 V_{i n}} \sum_{\mathrm{i}=1}^{\mathrm{N}} \Delta I_{i}^{2}
\end{aligned}
$$

From this quadratic equation, the transition time, $\Delta \mathrm{t}$, can be calculated and then the turn on interval of each phase is obtained by using (7).

It is important to notice that the transition time in equation (12) does not depend on the load current, but only on the difference of the current.

Fig. 5 shows one voltage transition and one phase current. Some of the earlier mentioned values like $\Delta \mathrm{I}_{\mathrm{i}}$ or $\mathrm{I}_{\mathrm{i}}$ can be observed.

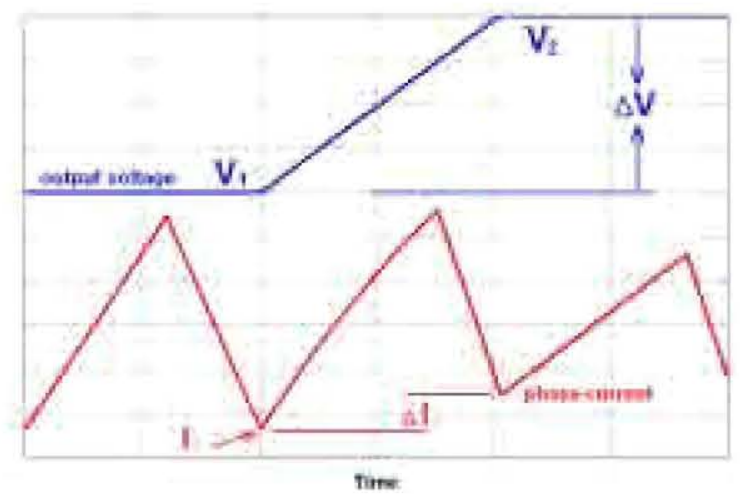

Figure 5. Simplified waveforms of the buck's output voltage and the current through one phase 
Fig. 6 shows simulated gate signals in a 4-phase converter when the transition from $0.5 \mathrm{~V}_{\text {in }}$ to $0.75 \mathrm{~V}_{\text {in }}$ is performed. It can be observed that in order to avoid any oscillation, it continues with PWM keeping the corresponding phase delays between the phases after the transient.

Fig. 7 shows the simulated output voltage and phase currents during the transient. The simulation has been performed in MATLAB and the input voltage of the converter is $20 \mathrm{~V}$, the transition is from $10 \mathrm{~V}$ to $15 \mathrm{~V}$, the inductor per each phase is $11 \mathrm{uH}$, while the output capacitor is $11 \mathrm{uF}$.

Table 1 shows the calculated times for each phase and different transitions for the same converter

\section{Filter design constraint}

For the given filter parameters $(\mathrm{L}, \mathrm{C})$, the transient time can be calculated. This transient time restrict the maximum frequency of the envelope that the converter can modulate. However, the design way is usually inversed. The maximum transient time is fixed by the application, then there are a plenty of possibilities for the filter parameters $(\mathrm{L}, \mathrm{C})$. The inductor limits the slew rate of current through the output capacitor, and the output capacitance value determines the charge that has to be delivered during the transient time to change the output voltage. Designing for very fast output voltage transient, a high ratio between $\mathrm{L}$ and $\mathrm{C}$ is suitable for charging output capacitor very fast. And it makes inductor size large. But the good regulation under the load current change requires a low ratio between $\mathrm{L}$ and $\mathrm{C}$. It reduces the size of inductor, but increase the inductor current ripple and output voltage ripple as well.

If the maximal slope of the envelope signal is known the selection of the $\mathrm{L}$ and $\mathrm{C}$ can be made by using this information and the equations from section $\mathrm{B}$. It can be shown that there is a following relationship between the converter's parameters:

$$
C<\frac{\Delta V}{6 L m^{2}}\left(6 V_{i n} n K-3 n V_{1}-n \Delta V-3 n K^{2} V_{i n}\right)-\frac{L}{2 V_{i n} \Delta V} \sum_{i=1}^{\mathrm{N}} \Delta I_{i}^{2}
$$

where $\mathrm{m}$ is the maximal slew rate of the buck's output voltage. Obviously the solution in this paper takes advantage of multiphase converter's feature, if it works in some particular duty cycles, which make completely ripple cancellation on output capacitor. With this feature, it allows to design the filter with low value of inductor and relatively high value of capacitor complying with the maximum transient time without suffering from the output voltage ripple. However, this analysis is outside the scope of this paper and it will be detail presented in one of the future papers.

\section{EXPERIMENTAL RESULTS}

A 4-phase prototype is used to validate the implementation of this minimum-time control strategy. The converter parameters are, $\mathrm{V}_{\mathrm{IN}}=20 \mathrm{~V}, \mathrm{~L}=11 \mathrm{uH}$ and $\mathrm{C}=11 \mathrm{uF}$. The state

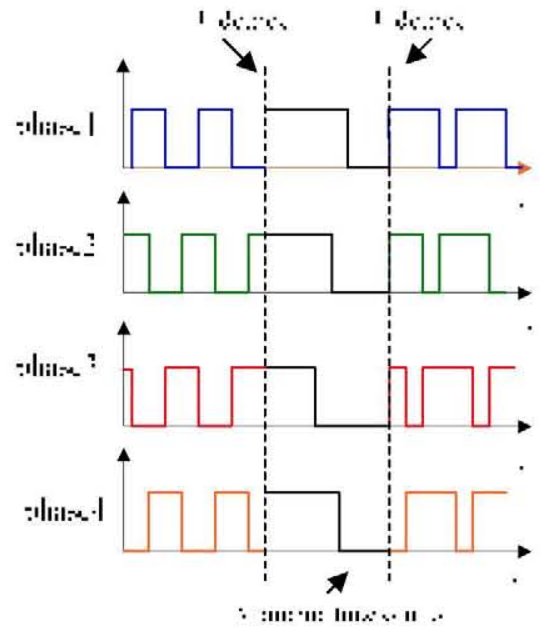

Figure 6. Control strategy for the voltage transition from $0.5 \mathrm{~V}_{\mathrm{IN}}$ to $0.75 \mathrm{~V}_{\mathrm{IN}}$

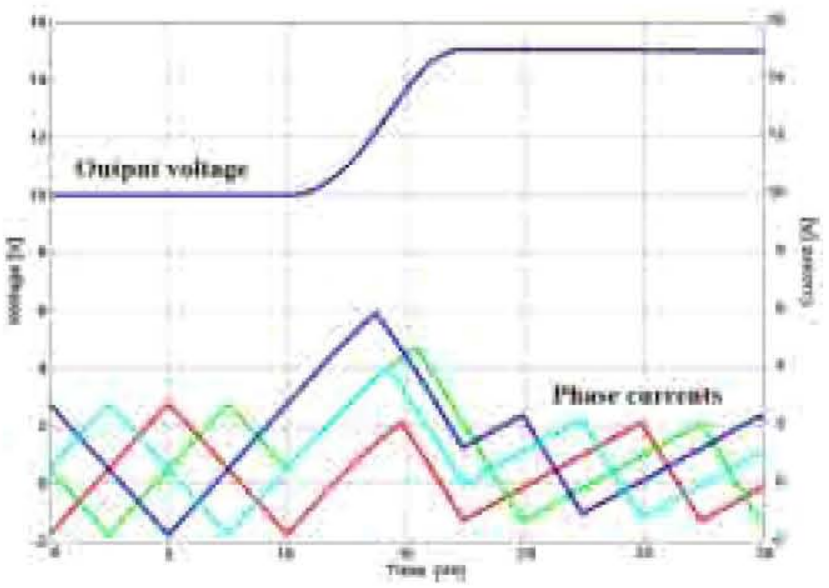

Figure 7. Simulation results for the voltage transition from $0.5 \mathrm{~V}_{\mathrm{IN}}$ to $0.75 \mathrm{~V}_{\mathrm{IN}}$

TABLE I. TRANSIENT TIME FOR EACH PHASES FOR DIFFERENT TRANSITIONS

\begin{tabular}{|c|c|c|c|c|}
\hline Transient & Phase & $t_{\mathrm{ON}}$ [us] & $\mathrm{t}_{\mathrm{OFF}}$ [us] & $\Delta \mathrm{t}$ [us] \\
\hline \multirow{4}{*}{$\begin{array}{c}\text { From } \\
0.25 \mathrm{~V}_{\mathrm{IN}} \text { to } \\
0.5 \mathrm{~V}_{\mathrm{NN}}\end{array}$} & $1^{\text {st }}$ & 2.5 & 5.02 & 7.52 \\
\hline & $2^{\text {nd }}$ & 1.88 & 5.64 & 7.52 \\
\hline & $3^{\text {rd }}$ & 3.76 & 3.76 & 7.52 \\
\hline & $4^{\text {th }}$ & 3.13 & 4.39 & 7.52 \\
\hline \multirow{4}{*}{$\begin{array}{c}\text { From } 0.5 \mathrm{~V}_{\mathrm{IN}} \\
\text { to } 0.75 \mathrm{~V}_{\mathrm{IN}}\end{array}$} & $1^{\text {st }}$ & 5.01 & 2.51 & 7.52 \\
\hline & $2^{\text {nd }}$ & 4.38 & 3.14 & 7.52 \\
\hline & $3^{\text {rd }}$ & 3.76 & 3.76 & 7.52 \\
\hline & $4^{\text {thi }}$ & 5.64 & 1.88 & 7.52 \\
\hline \multirow{4}{*}{$\begin{array}{l}\text { From } \\
0.75 \mathrm{~V}_{\mathrm{IN}} \text { to } \\
0.5 \mathrm{~V}_{\mathrm{IN}}\end{array}$} & $1^{\text {st }}$ & 5.01 & 2.51 & 7.52 \\
\hline & $2^{\text {nd }}$ & 4.38 & 3.14 & 7.52 \\
\hline & $3^{\text {rd }}$ & 3.76 & 3.76 & 7.52 \\
\hline & $4^{\text {th }}$ & 5.64 & 1.88 & 7.52 \\
\hline \multirow{4}{*}{$\begin{array}{c}\text { From } 0.5 \mathrm{~V}_{\mathrm{IN}} \\
\text { to } 0.25 \mathrm{~V}_{\mathrm{IN}}\end{array}$} & $1^{\mathrm{s}}$ & 2.5 & 5.02 & 7.52 \\
\hline & $2^{\text {nd }}$ & 1.88 & 5.64 & 7.52 \\
\hline & $3^{\text {rd }}$ & 3.76 & 3.76 & 7.52 \\
\hline & $4^{\text {thi }}$ & 3.13 & 4.39 & 7.52 \\
\hline
\end{tabular}




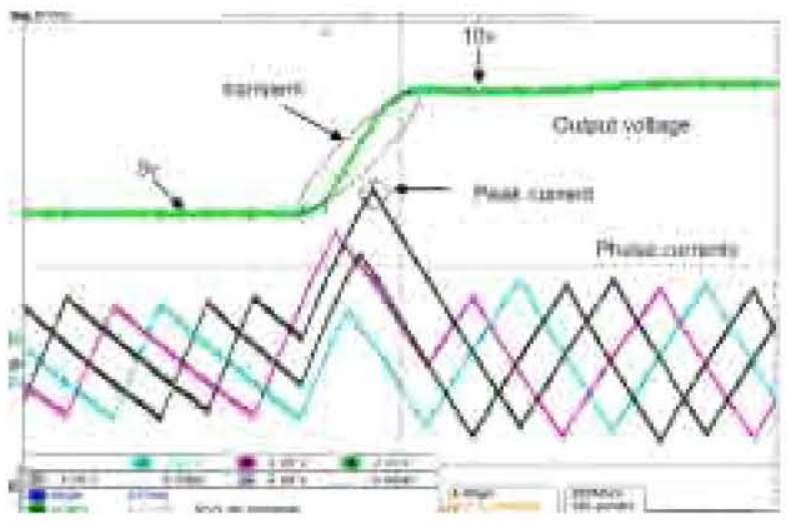

Fig. 8 output voltage step from $5 \mathrm{~V}$ to $10 \mathrm{~V}$ at $1 \mathrm{~A}$ load current, $100 \mathrm{kHz}$

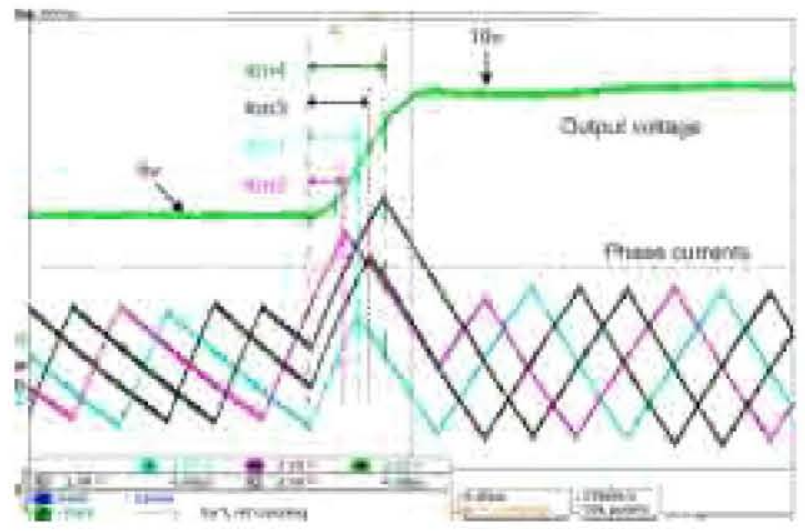

Fig. 9 output voltage step from $5 \mathrm{~V}$ to $10 \mathrm{~V}$ at $2 \mathrm{~A}$ load current, $100 \mathrm{kHz}$

transient can be output voltage from $5 \mathrm{~V}$ to $10 \mathrm{~V}(25 \%$ duty cycle to $50 \%$ duty cycle), from $10 \mathrm{~V}$ to $15 \mathrm{~V}(50 \%$ duty cycle to $75 \%$ duty cycle) in Fig. 8, Fig. 9 and Fig. 10. The other parameter of the state should be inductor current. Thanks to multiphase with ripple cancellation, it is not necessary to know the inductor current value before and after the transient, but to know the difference of the current is enough. It can be seen from the equations in section II. The sum of the initial current can be cancelled by load current. This indicates that the control strategy is not influenced by the current unbalance.

The control strategy is implemented on FPGA. Four counters are used in the program to generate PWM signal. With different initial counter value, four PWM can work in interleaved way. There is a process in the program to synchronize the transient with one of the PWM signal by the counter. At the end of the transient time, the new initial value has to be given to the counter. The on-time and off-time in the transient required are in the look-up table in the program. The control is tested in open-loop, to validate the idea of the minimum time control.

Table II shows the experimental transient time. Comparing with table 1 , there are some differences, because the model is idea one and it introduces some errors. However, it still makes a good starting point to find real transient time. More accurate model including the parasitic

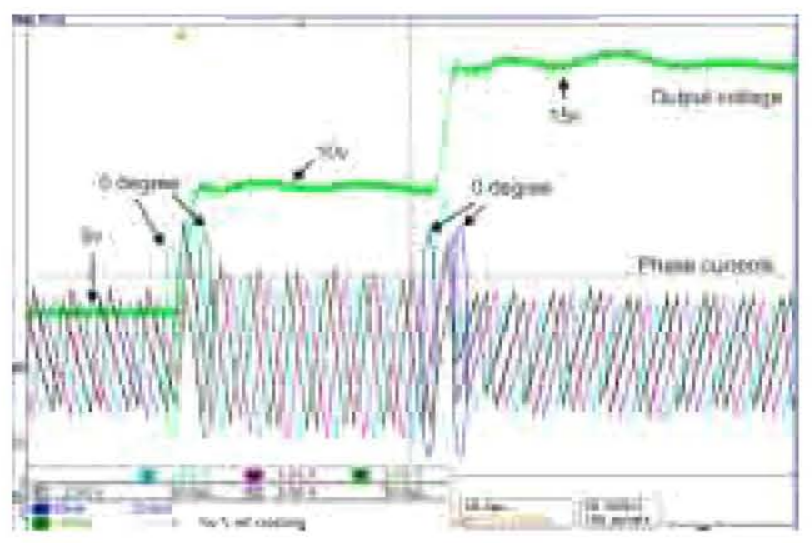

Fig. 10 output voltage step from $5 \mathrm{~V}$ to $10 \mathrm{~V}$ and from $10 \mathrm{~V}$ to $15 \mathrm{~V}$ at $1 \mathrm{~A}$ load, $100 \mathrm{kHz}$

TABLE II. THE EXPERIMENT TRANSIENT TIME

\begin{tabular}{|c|c|c|c|c|}
\hline Transient & Phase & $t_{\mathrm{ON}}$ [us] & $\mathrm{t}_{\mathrm{OFF}}$ [us] & $\Delta \mathrm{t}$ [us] \\
\hline \multirow{4}{*}{$\begin{array}{c}\text { From } \\
0.25 \mathrm{~V}_{\mathrm{IN}} \\
\text { to } 0.5 \mathrm{~V}_{\mathrm{IN}}\end{array}$} & $1^{\mathrm{st}}$ & 2.5 & 4.18 & 6.68 \\
\hline & $2^{\text {nd }}$ & 1.82 & 4.86 & 6.68 \\
\hline & $3^{\text {rd }}$ & 3.98 & 2.7 & 6.68 \\
\hline & $4^{\text {th }}$ & 3.15 & 3.53 & 6.68 \\
\hline \multirow{4}{*}{$\begin{array}{c}\text { From } \\
0.5 \mathrm{~V}_{\mathrm{IN}} \text { to } \\
0.75 \mathrm{~V}_{\mathrm{IN}}\end{array}$} & $1^{\text {st }}$ & 4.96 & 2.04 & 7 \\
\hline & $2^{\text {nd }}$ & 4.41 & 2.59 & 7 \\
\hline & $3^{\text {rd }}$ & 3.88 & 3.12 & 7 \\
\hline & $4^{\text {th }}$ & 5.58 & 1.42 & 7 \\
\hline \multirow{4}{*}{$\begin{array}{l}\text { From } \\
0.75 \mathrm{~V}_{\mathrm{IN}} \\
\text { to } 0.5 \mathrm{~V}_{\mathrm{IN}}\end{array}$} & $1^{\mathrm{st}}$ & 4.96 & 2.04 & 7 \\
\hline & $2^{\text {nd }}$ & 4.41 & 2.59 & 7 \\
\hline & $3^{\text {rd }}$ & 3.88 & 3.12 & 7 \\
\hline & $4^{\text {th }}$ & 5.58 & 1.42 & 7 \\
\hline \multirow{4}{*}{$\begin{array}{c}\text { From } \\
0.5 \mathrm{~V}_{\mathrm{IN}} \text { to } \\
0.25 \mathrm{~V}_{\mathrm{IN}}\end{array}$} & $1^{\mathrm{st}}$ & 2.5 & 4.18 & 6.68 \\
\hline & $2^{\text {nd }}$ & 1.82 & 4.86 & 6.68 \\
\hline & $3^{\text {rd }}$ & 3.98 & 2.7 & 6.68 \\
\hline & $4^{\text {th }}$ & 3.15 & 3.53 & 6.68 \\
\hline
\end{tabular}

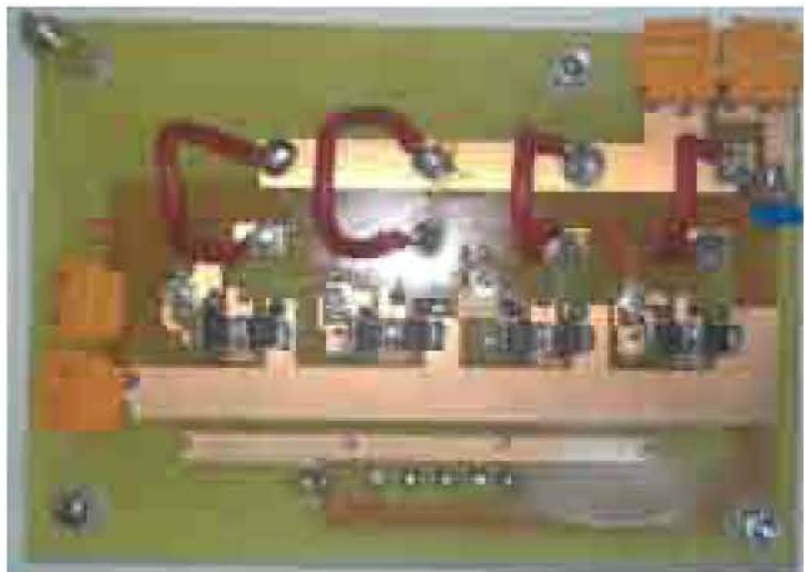

Fig. 11 The prototype of the 4-phase buck converter

resistance needed to calculate the transient time, which can be the following work. 


\section{FUTURE WORK}

The concept of the minimum time transient will be applied for the envelopes with high slew rate. In order to achieve it, it is necessary to use significantly higher frequency so that the output filter can be small, because the transient time is directly proportional to its value. Fig. 11 shows a photograph of the prototype that has been developed and the switching frequency that is applied is $2 \mathrm{MHz}$.

Another important issue of the future prototypes is the number of the phases that are used. To optimize the number of the phases has been considered for the desired voltage slew rate, complexity of the system and its size.

\section{CONCLUSIONS}

Modulating the envelope to improve the efficiency in RF system is an active research topic. There are a lot of challenges to optimize the performance of envelope modulator. In this paper, the envelope amplifier includes an open-loop multiphase buck converter in series with a linear regulator. The multiphase buck converter is analyzed to meet the requirement for the variations of output voltage. The methodology of calculating the parameters for this control have been presented. The theoretical results are verified in practice using a 4-phase multiphase converter. The minimum time control strategy can be obtain by transient model of the multiphase converter. This control strategy has simple transient time calculation and easy hardware implementation. The trade-off between the transient time and the output filter parameters is considerate also. In the design, the relatively low switching frequency and low value of inductor can be used without the problem of ripple, because of interleaved multiphase converter and the particular duty cycles that are used.

\section{REFERENCES}

[1] V. Yousefzadeh, N. Wang, "A digitally controlled DC/DC converter for an RF power amplifier", IEEE Transactions on Power Electronics, Volume 21, No. 1, January 2006, Pages: 164-172.

[2] A. Soto, J.A. Oliver, J.A. Cobos, J. Cezon, F. Arevalo, "Power supply for a radio transmitter with modulated supply voltage", Applied Power Electronics Conference, APEC '04, Volume: 1, Feb. 2004 Pages:392 - 398 .

[3] V. Yousefzadeh, E. Alarcon, D. Maksimović, "Three-level buck converter for envelope tracking in RF power amplifiers," IEEE Trans. on Power Electronics, Volume:21, Issue: 2, March 2006, Pages:549 552.

[4] V. Yousefzadeh, E. Alarcon, D. Maksimović, "Band separation and efficiency optimization in linear-assisted switching power amplifiers", IEEE Power Electronics Specialists Conference, 2006 Pages:1-7.

[5] M. Vasić, O. Garcia, J.A. Oliver, P. Alou, D. Diaz, J.A. Cobos, "Multilevel Power Supply for High Efficiency RF Amplifier", Proc. of the 24th Annual IEEE Applied Power Electronics Conference, APEC '09, February 2009.

[6] M. Vasić, O. Garcia, J.A. Oliver.P. Alou, D. Diaz, J.A. Cobos, "Switching capacities based envelope amplifier for high efficiency RF amplifiers" Proc. of the 25th Annual IEEE Applied Power Electronics Conference, pp.723-728

[7] M.C. Gonzalez, M. Vasić, P. Alou, O. Garcia, J.A. Oliver, J.A Cobos, "Power Analog to Digital Converter for Voltage Scaling Applications", Proc. of the 25th Annual IEEE Applied Power Electronics Conference, Feb. 2010 Pages:271 - 276.

[8] M. Rodríguez, P.F. Miaja, J. Sebastián, D. Maksimović, "Mismatcherror noise-shaping based digital multiphase modulator", IEEE COMPEL Conference, June. 2010

[9] A. Soto, P. Alou, J.A Cobos, J. Uceda, "Analysis of the buck converter for Scaling the supply voltage of digital circuits", IEEE Transactions on Power Electronics, Volume 22, 6, November 2007 Page(s):2432 - 2440

[10] J. Alico, A. Prodic, "Multiphase optimal response mixed-signal current-programmed mode controller", IEEE Applied Power Electronics Conference, Feb. 2010 Pages:1113-1118 